\title{
Effects of Hypercapnia on Myocardial Blood Flow in Healthy Human Subjects
}

\author{
Matthieu Pelletier-Galarneau ${ }^{1-3}$, Robert A. deKemp ${ }^{2,3}$, Chad R.R.N. Hunter ${ }^{2,3}$, Ran Klein ${ }^{2,3}$, Michael Klein ${ }^{4}$, \\ Joel Ironstone ${ }^{4}$, Joseph A. Fisher ${ }^{5}$, and Terrence D. Ruddy ${ }^{1-3}$ \\ ${ }^{I}$ Division of Nuclear Medicine, The Ottawa Hospital, Ottawa, Ontario, Canada; ${ }^{2}$ Department of Medicine, University of Ottawa, \\ Ottawa, Ontario, Canada; ${ }^{3}$ Division of Cardiology, University of Ottawa Heart Institute, Ottawa, Ontario, Canada; ${ }^{4}$ Thornhill \\ Research Inc., Toronto, Ontario, Canada; and ${ }^{5}$ Department of Anesthesiology, University of Toronto, Ottawa, Ontario, Canada
}

\begin{abstract}
Elevation of the end-tidal partial pressure of $\mathrm{CO}_{2}\left(\mathrm{P}_{\mathrm{ET}} \mathrm{CO}_{2}\right)$ increases cerebral and myocardial blood flow (MBF), suggesting that it may be a suitable alternative to pharmacologic stress or exercise for myocardial perfusion imaging. The purpose of this study was to document the pharmacodynamics of $\mathrm{CO}_{2}$ for MBF using prospective end-tidal targeting to precisely control arterial $\mathrm{PCO}_{2}$ and PET to measure the outcome variable, MBF. Methods: Ten healthy men underwent serial ${ }^{82} \mathrm{Rb} \mathrm{PET} / \mathrm{CT}$ imaging. Imaging was performed at rest and during 6-min hypercapnic plateaus (baseline; $\mathrm{P}_{\mathrm{ET}} \mathrm{CO}_{2}$ at 50 , 55 , and $60 \mathrm{~mm} \mathrm{Hg}$; repeat of $\mathrm{P}_{\mathrm{ET} \mathrm{CO}_{2}}$ at $60 \mathrm{~mm} \mathrm{Hg}$; and repeat of baseline). MBF was measured using ${ }^{82} \mathrm{Rb}$ injected $3 \mathrm{~min}$ after the beginning of hypercapnia and a 1-tissue-compartment model with flow-dependent extraction correction. Results were compared with those obtained during an adenosine stress test $(140 \mu \mathrm{g} / \mathrm{kg} / \mathrm{min})$. Results: Baseline $\mathrm{P}_{\mathrm{ETCO}}$ was $38.9 \pm 0.8$ (mean $\pm \mathrm{SD}$ ) $\mathrm{mm} \mathrm{Hg}$ (range, $35-43 \mathrm{~mm} \mathrm{Hg}$ ). All $\mathrm{P}_{\mathrm{ETCO}}$ targets were sustained, with SDs of less than $1.5 \mathrm{~mm}$ Hg. Heart rate, systolic blood pressure, rate $\times$ pressure product, and respiratory frequency increased with progressive hypercapnia. MBF increased significantly at each level of hypercapnia to 1.92 -fold over baseline $(0.86 \pm 0.24$ vs. $0.45 \pm 0.08 \mathrm{~mL} / \mathrm{min} / \mathrm{g}$; $P=0.002)$ at a $\mathrm{P}_{\mathrm{ETCO}}$ of $60 \mathrm{~mm} \mathrm{Hg}$. MBF after the administration of adenosine was significantly greater than that with the maximal hypercapnic stimulus ( 2.00 vs. $0.86 \mathrm{~mL} / \mathrm{min} / \mathrm{g} ; P<0.0001)$. Conclusion: To our knowledge, this study is the first to assess the response of MBF to different levels of hypercapnia in healthy humans with PET. MBF increased with increasing levels of hypercapnia; MBF at a $\mathrm{P}_{\mathrm{ET} C \mathrm{CO}_{2}}$ of $60 \mathrm{~mm} \mathrm{Hg}$ was double that at baseline.
\end{abstract}

Key Words: hypercapnia; myocardial blood flow; adenosine; myocardial perfusion imaging; rubidium; end-tidal partial pressure of $\mathrm{CO}_{2}$

J Nucl Med 2018; 59:100-106

DOI: 10.2967/jnumed.117.194308

$\mathbf{L}$

ittle is known about the effects of hypercapnia (arterial $\mathrm{PCO}_{2}$ $\left[\mathrm{PaCO}_{2}\right]$ of $>45 \mathrm{~mm} \mathrm{Hg}$ ) on myocardial blood flow (MBF) in humans. The effects of $\mathrm{PaCO}_{2}$ on MBF were first studied more than $100 \mathrm{y}$ ago in dogs, in which coronary blood flow increased with hypercapnia $(1,2)$. The authors attributed the increased MBF

Received Apr. 4, 2017; revision accepted Jun. 8, 2017.

For correspondence or reprints contact: Terrence D. Ruddy, 40 Ruskin, Room H1220, Ottawa, Ontario, Canada K1Y4W7.

E-mail: truddy@ottawaheart.ca

Published online Jun. 15, 2017.

COPYRIGHT (C 2018 by the Society of Nuclear Medicine and Molecular Imaging. to smooth muscle relaxation leading to decreased coronary resistance. These results were reproduced using different MBF measurement techniques in different animal models (3-6).

Yang et al. were the first to systematically examine the doseresponse characteristics of controlled hypercapnia on absolute $\mathrm{MBF}$ in humans using precise $\mathrm{CO}_{2}$ targeting (7). They studied the effect of a single 10-mm $\mathrm{Hg}$ increase in the end-tidal partial pressure of $\mathrm{CO}_{2}\left(\mathrm{P}_{\mathrm{ET}} \mathrm{CO}_{2}\right)$ on $\mathrm{MBF}$ in healthy humans using myocardial blood oxygen level-dependent MRI, a surrogate of MBF (7). They demonstrated that hypercapnia created a hyperemic response similar to that reported for adenosine infusion. Studies in canines demonstrated the dynamic response of MBF over a range of 30-60 mm Hg. More recently, Yang et al. showed no significant difference between the responses to hypercapnia and adenosine infusion in canines without coronary stenosis, with MBF doubling over that at baseline (8).

Other studies investigating the effects of hypercapnia on MBF in humans were performed with dissimilar protocols and produced variable results. None provided the dynamic range of response of MBF to graded $\mathrm{P}_{\mathrm{ET}} \mathrm{CO}_{2}$. In this study, we assessed the relationship between graded levels of $\mathrm{P}_{\mathrm{ET}} \mathrm{CO}_{2}$ and increases in $\mathrm{MBF}$, as measured using PET imaging. The dose-response relationship between $\mathrm{P}_{\mathrm{ETCO}}$ and $\mathrm{MBF}$ is a prerequisite for using $\mathrm{CO}_{2}$ as a noninvasive stimulus in the measurement of myocardial flow reserve (MFR).

\section{MATERIALS AND METHODS}

\section{Study Population}

Eleven healthy male volunteers, screened by a clinical history and physical examination, were recruited for this study. One recruited subject did not attend on imaging day and was therefore excluded. Participants had no history of obstructive coronary artery disease (CAD) and had no symptoms of CAD or heart failure. Participants provided written informed consent, and the study was approved by the Ottawa Health Science Network Research Ethics Board. Participants were instructed to avoid caffeinated drinks for $24 \mathrm{~h}$ before imaging.

\section{PET Imaging}

At present, MBF may be assessed noninvasively with several methods. Transthoracic echocardiography can estimate epicardial coronary artery flow reserve, and MRI can approximate global and regional flow reserve. Nevertheless, PET imaging remains the clinical gold standard to which other noninvasive techniques are compared and validated. The accuracy and repeatability of PET have made it the method of choice for quantifying absolute MBF (9).

All participants underwent a baseline rest ${ }^{82} \mathrm{Rb}$ PET scan to quantify MBF and low-dose CT for attenuation correction. After this baseline study, serial ${ }^{82} \mathrm{Rb}$ PET scans using 3 levels of $\mathrm{P}_{\mathrm{ET}} \mathrm{CO}_{2}$ (50, 55, and $60 \mathrm{~mm} \mathrm{Hg}$ ), a suitable surrogate of $\mathrm{PaCO}_{2}$ (10), were acquired. Using 
sequential gas delivery, $\mathrm{P}_{\mathrm{ET}} \mathrm{CO}_{2}$ levels were within $\pm 1 \mathrm{~mm} \mathrm{Hg}$ of their arterial equivalents (11). The $60-\mathrm{mm} \mathrm{Hg}$ level scan was repeated after a rest period of at least $10 \mathrm{~min}$. A second rest ${ }^{82} \mathrm{Rb}$ PET scan was performed after a return to normocapnia. For every level of $\mathrm{P}_{\mathrm{ET}} \mathrm{CO}_{2}$, hypercapnia was maintained for 6 min. ${ }^{82} \mathrm{Rb}$ infusion and PET acquisition were started 3 min after the beginning of hypercapnia. This acquisition was followed by an adenosine stress ${ }^{82} \mathrm{Rb}$ PET scan at least 20 min later (Fig. 1). A total of $7{ }^{82} \mathrm{Rb}$ PET scans per participant were performed within $90 \mathrm{~min}$.

Heart rate (HR) and blood pressure were measured 1 to $3 \mathrm{~min}$ before stress, immediately before tracer injection, and 3 to $5 \mathrm{~min}$ after injection (Spot Vital Signs Device; Welch Allyn). Additionally, during pharmacologic and hypercapnic stresses, HR was measured every minute using 12-lead echocardiography (CardioSoft Diagnostic System; GE). The rate $\times$ pressure product (RPP) calculation was performed using the average HR and systolic blood pressure (SBP) at peak stress and after tracer infusion.

${ }^{82} \mathrm{Rb}$ PET imaging was performed according to the University of Ottawa Heart Institute standard clinical protocol previously described (12). In brief, participants were positioned in a 3-dimensional PET system (GE Discovery 690 PET/CT). The initial rest PET scan included low-dose CT for attenuation correction (fast helical, $1.5 \mathrm{~s}$, $120 \mathrm{kVp}$ with axial and angular $\mathrm{mA}$ modulation at a noise index of 50). After ${ }^{82} \mathrm{Rb}$ was administered at $10 \mathrm{MBq} / \mathrm{kg}$ intravenously over $30 \mathrm{~s}$, PET imaging was performed over a period of $6 \mathrm{~min}$. MBF was quantified using a 1-tissue-compartment model with flow-dependent extraction correction (12). Polar maps representing MBF were generated for each rest and stress state using validated software (FlowQuant; University of Ottawa Heart Institute) (13). Corrected MBF values were calculated using the population average rest RPP according to the following formula: corrected $\mathrm{MBF}=(\mathrm{MBF} \times$ average $\mathrm{RPP}) /$ subject RPP. MFR were calculated by dividing MBF values by rest-MBF. All presented MBF and MFR were unadjusted except when noted otherwise.

\section{Hypercapnia}

Until recently, precise modulation of $\mathrm{PaCO}_{2}$ and arterial oxygen tension $\left(\mathrm{PaO}_{2}\right)$ levels could be achieved only by changing the concentrations of inspired gases. These fixed inspired gas methods are affected by variations in breathing patterns (frequency and tidal volume), leading to variability in end-tidal gas concentrations (14). A new approach of breath-by-breath control of arterial blood gases using sequential gas delivery $(10,11,15)$ enabled the automated prospective control of arterial blood gases (16) independently of the subject's ventilation or pattern of breathing. Using sequential gas delivery, it is possible to maintain a euoxic-hypercapnic state at any level for several minutes with minimal discomfort for the subject (17) - conditions needed for the precise assessment of MBF using PET imaging.
$\mathrm{P}_{\mathrm{ETCO}}$ and end-tidal $\mathrm{O}_{2}$ partial pressure targets were achieved using prospective end-tidal gas targeting with previously described algorithms (11). These algorithms were applied by a computerized gas blender (RespirAct; Thornhill Research) that had $\mathrm{PCO}_{2}$ and $\mathrm{PO}_{2}$ sensors and that was connected to a sequential gas delivery breathing circuit (15). Pilot studies with the computerized gas blender showed that a $\mathrm{PCO}_{2}$ of $60 \mathrm{~mm} \mathrm{Hg}$ could be tolerated consistently for several minutes. Therefore, this level was chosen as the upper $\mathrm{PCO}_{2}$ target for the study, so that a dose-response relationship could be discerned and provide an indication of whether the response of MBF to $\mathrm{PCO}_{2}$ plateaued as $\mathrm{PCO}_{2}$ approached $60 \mathrm{~mm} \mathrm{Hg}$.

For this study, 3 levels of $\mathrm{P}_{\mathrm{ETCO}}(50,55$, and $60 \mathrm{~mm} \mathrm{Hg})$ were targeted and maintained over $6 \mathrm{~min}$ while euoxia was maintained (end-tidal $\mathrm{O}_{2}$ partial pressure of $100 \mathrm{~mm} \mathrm{Hg}$ ). Tidal $\mathrm{PCO}_{2}$ and $\mathrm{Po}_{2}$ were monitored continuously and recorded. Before imaging, the participants' $\mathrm{PCO}_{2}$ was increased to $60 \mathrm{~mm} \mathrm{Hg}$ for $6 \mathrm{~min}$ to familiarize them with the sensation of hypercapnia and confirm their tolerance for the change. Baseline $\mathrm{P}_{\mathrm{ETCO}}$ levels were estimated using average $\mathrm{P}_{\mathrm{ETCO}}$ measurements after initial application of the mask and before hypercapnia. Baseline respiratory frequencies $(f)$ were calculated after the participant was positioned under the camera while wearing the mask.

\section{Study Tolerability}

Subjects graded the discomfort associated with hypercapnia and adenosine on a subjective scale from 0 to 10 , with 0 representing no discomfort and 10 representing intolerable discomfort.

\section{Statistical Analysis}

One-way repeated-measures ANOVAs were conducted before comparison of the different imaging states using the first baseline study and the first maximal hypercapnic stimulus $(60 \mathrm{~mm} \mathrm{Hg})$. When data for a participant were missing, the entire dataset for that participant was excluded from repeated-measures ANOVAs. Post hoc analyses were conducted using paired Student $t$ tests with Bonferroni-Holm sequential corrections for multiple comparisons with the dataset for all patients. A total of 8 comparisons were performed for the variables of interest (baseline vs. $50 \mathrm{~mm} \mathrm{Hg}$, baseline vs. $60 \mathrm{~mm} \mathrm{Hg}, 50 \mathrm{~mm} \mathrm{Hg}$ vs. $55 \mathrm{~mm} \mathrm{Hg}, 55 \mathrm{~mm} \mathrm{Hg}$ vs. $60 \mathrm{~mm} \mathrm{Hg}$, $60 \mathrm{~mm} \mathrm{Hg}$ vs. repeat $60 \mathrm{~mm} \mathrm{Hg}, 60 \mathrm{~mm} \mathrm{Hg}$ vs. adenosine, baseline vs. repeat baseline, and repeat baseline vs. adenosine). Tolerability levels were compared using paired $t$ tests. The average MFR was computed from the individual MFRs measured in each participant.

Unless otherwise specified, the results are presented as mean \pm SD. $P$ values of less than 0.05 were considered statistically significant.

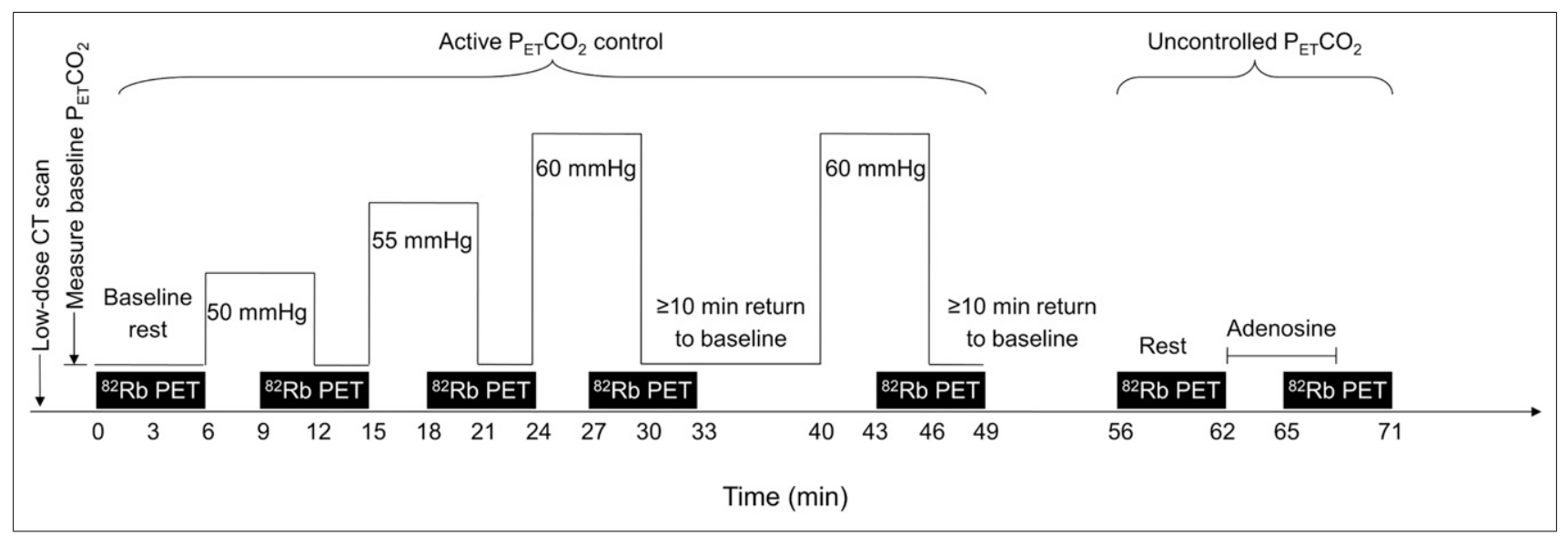

FIGURE 1. Sequence of imaging during single visit. 
TABLE 1

Summary of Results

\begin{tabular}{|c|c|c|c|c|c|c|c|c|}
\hline Parameter & $\begin{array}{l}\text { Baseline } \\
(n=10)\end{array}$ & $\begin{array}{l}\text { Repeat } \\
\text { baseline } \\
(n=10)\end{array}$ & $\begin{array}{c}50 \mathrm{~mm} \mathrm{Hg} \\
(n=10)\end{array}$ & $\begin{array}{c}55 \mathrm{~mm} \mathrm{Hg} \\
(n=9)\end{array}$ & $\begin{array}{c}60 \mathrm{~mm} \mathrm{Hg} \\
(n=9)\end{array}$ & $\begin{array}{c}\text { Repeat } \\
60 \mathrm{~mm} \mathrm{Hg} \\
(n=8)\end{array}$ & $\begin{array}{l}\text { Adenosine } \\
(n=10)\end{array}$ & $\begin{array}{c}P \text { value } \\
\text { determined } \\
\text { by ANOVA* }\end{array}$ \\
\hline $\mathrm{P}_{\mathrm{ET}} \mathrm{CO}_{2}(\mathrm{~mm} \mathrm{Hg})$ & $38.9 \pm 2.4$ & $\mathrm{~N} / \mathrm{A}$ & $49.9 \pm 0.1$ & $54.8 \pm 0.3$ & $59.4 \pm 1.2$ & $59.7 \pm 0.5$ & $\mathrm{~N} / \mathrm{A}$ & $<0.0001$ \\
\hline HR (beats/min) & $57 \pm 8$ & $59 \pm 8$ & $62 \pm 7$ & $66 \pm 9$ & $68 \pm 10$ & $69 \pm 8$ & $76 \pm 10$ & $<0.001$ \\
\hline$f$ (breaths/min) & $12 \pm 4$ & $\mathrm{~N} / \mathrm{A}$ & $17 \pm 5$ & $19 \pm 4$ & $22 \pm 5$ & $23 \pm 6$ & $\mathrm{~N} / \mathrm{A}$ & $<0.001$ \\
\hline $\mathrm{SBP}(\mathrm{mm} \mathrm{Hg})$ & $109 \pm 13$ & $117 \pm 13$ & $119 \pm 15$ & $123 \pm 11$ & $131 \pm 12$ & $125 \pm 8$ & $121 \pm 13$ & $<0.001$ \\
\hline $\mathrm{DBP}(\mathrm{mm} \mathrm{Hg})$ & $65 \pm 11$ & $71 \pm 11$ & $68 \pm 12$ & $70 \pm 10$ & $74 \pm 13$ & $71 \pm 7$ & $70 \pm 12$ & 0.196 \\
\hline $\begin{array}{l}\text { RPP } \\
\quad(\mathrm{bpm} \times \mathrm{mm} \mathrm{Hg})\end{array}$ & $6,135 \pm 1,650$ & $6,900 \pm 1,165$ & $7,140 \pm 1,495$ & $7,487 \pm 1,503$ & $8,256 \pm 1,493$ & $7,666 \pm 1,240$ & $9,123 \pm 1,632$ & 0.001 \\
\hline $\mathrm{MBF}(\mathrm{mL} / \mathrm{min} / \mathrm{g})$ & $0.45 \pm 0.08$ & $0.52 \pm 0.10$ & $0.62 \pm 0.20$ & $0.76 \pm 0.21$ & $0.86 \pm 0.24$ & $0.89 \pm 0.24$ & $2.00 \pm 0.34$ & $<0.0001$ \\
\hline $\begin{array}{l}\text { Corrected MBF } \\
(\mathrm{mL} / \mathrm{min} / \mathrm{g})\end{array}$ & $0.44 \pm 0.045$ & $0.47 \pm 0.09$ & $0.51 \pm 0.15$ & $0.57 \pm 0.08$ & $0.59 \pm 0.15$ & $0.64 \pm 0.19$ & $1.37 \pm 0.31$ & $<0.0001$ \\
\hline MFR & & & $1.37 \pm 0.317$ & $1.68 \pm 0.33$ & $1.97 \pm 0.45$ & $2.12 \pm 0.48$ & $4.53 \pm 0.70$ & $<0.0001$ \\
\hline
\end{tabular}

*Three participants for whom data were missing were excluded from repeated-measures ANOVA. $n=$ number of participants; N/A = not available.

Values (other than $P$ values) are presented as mean $\pm \mathrm{SD}$.

Statistical analysis was performed using GraphPad Prism version 6.01 for Windows (GraphPad Software) and MedCalc for Windows, version 12.2 (MedCalc Software).

\section{RESULTS}

\section{Population}

The participants' age, weight, height, and body mass index were $30 \pm 12 \mathrm{y}, 84.8 \pm 11.2 \mathrm{~kg}, 178 \pm 8 \mathrm{~cm}$, and $26.9 \pm 4.3 \mathrm{~kg} / \mathrm{m}^{2}$, respectively. All participants had normal 12-lead echocardiography results before entering the study. The measured baseline $\mathrm{P}_{\mathrm{ETCO}}$ was $38.9 \pm 0.8 \mathrm{~mm} \mathrm{Hg}$ (range, $35-43 \mathrm{~mm} \mathrm{Hg}$ ). For 1 participant, imaging at the $55-\mathrm{mm} \mathrm{Hg}$ level was not acquired for technical reasons; imaging at the $60-\mathrm{mm} \mathrm{Hg}$ level was not acquired for another participant because of an inability to maintain a stable $\mathrm{P}_{\mathrm{ET} \mathrm{CO}_{2}}$. Data from these 2 participants were excluded from the repeated-measures ANOVAs. For 2 other participants, repeat $60-\mathrm{mm} \mathrm{Hg}$ acquisitions were not obtained.

\section{Hypercapnic Stimulus}

All $\mathrm{P}_{\mathrm{ETCO}_{2}}$ targets were attained, with SDs of less than $1.5 \mathrm{~mm} \mathrm{Hg}$ (Table 1). A representative $\mathrm{P}_{\mathrm{ETCO}}$ tracing presented in Figure 2 shows a rapid increase in the $\mathrm{P}_{\mathrm{ETCO}}$ to the target level and then a stable $\mathrm{P}_{\mathrm{ETCO}}$ at all target levels.

\section{Hemodynamic Parameters}

HR, SBP, $f$, and RPP increased with progressive levels of hypercapnia (Table 1; Fig. 3). There was a moderate correlation between RPP and MBF $\left(R^{2}=0.41 ; P<0.0001\right)$ (Fig. 4A). Diastolic blood pressure (DBP) did not change ( $P=0.2$, as determined by ANOVA).

\section{MBF and MFR}

MBF increased $92 \%$ with the maximal hypercapnic stimulus $(0.86 \pm 0.24$ vs. $0.45 \pm 0.08 \mathrm{~mL} / \mathrm{min} / \mathrm{g} ; P=0.002)$ (Fig. 5). Increases in $\mathrm{P}_{\mathrm{ETCO}_{2}}$ and $\mathrm{MFR}$ were significantly correlated $\left(R^{2}=0.43 ; P<0.0001\right)$ (Fig. 4B). The dose-response relationship between MBF and $\mathrm{P}_{\mathrm{ETCO}}$ levels is shown in Figure $4 \mathrm{C}$. MBF was significantly greater at $50 \mathrm{~mm} \mathrm{Hg}$ than at baseline $(P=0.030)$, at $55 \mathrm{~mm} \mathrm{Hg}$ than at $50 \mathrm{~mm} \mathrm{Hg}(P=0.014)$, at $60 \mathrm{~mm} \mathrm{Hg}$ than at $55 \mathrm{~mm} \mathrm{Hg}(P=0.011)$, and at $60 \mathrm{~mm} \mathrm{Hg}$ than at baseline $(P=0.002)$. There was a similar dose-response relationship for corrected MBF (Fig. 4C). Corrected MBF values were significantly lower than noncorrected values at $50 \mathrm{~mm} \mathrm{Hg}(P=0.032)$, $55 \mathrm{~mm} \mathrm{Hg}(P=0.0174)$, and $60 \mathrm{~mm} \mathrm{Hg}(P=0.002)$. MFR was significantly higher at $55 \mathrm{~mm} \mathrm{Hg}$ than at $50 \mathrm{~mm} \mathrm{Hg}(1.70$ vs. 1.38 ; $P=0.005)$ and significantly higher at $60 \mathrm{~mm} \mathrm{Hg}$ than at $55 \mathrm{~mm} \mathrm{Hg}$ (1.91 vs. $1.70 ; P=0.005)$.

Multiple regression analyses were conducted to examine the relationship between $\mathrm{MBF}$ and 2 potential predictors, $\mathrm{P}_{\mathrm{ETCO}}$ and RPP. The multiple regression model with 2 predictor variables produced an $R^{2}$ of 0.55 , an $F_{2,35}$ of 21.23 , and a $P$ value of less than 0.001. Both $\mathrm{P}_{\mathrm{ETCO}_{2}}(\beta=0.01285 ; P=0.0022)$ and RPP $(\beta=$ $0.00006 ; P=0.0014$ ) had significant positive regression weights.

\section{Adenosine}

Adenosine increased MBF in all subjects, to $2.00 \pm 0.34 \mathrm{~mL} / \mathrm{min} / \mathrm{g}$, resulting in an MFR of $4.53 \pm 0.70$ (range, 3.56-5.73). The adenosine-induced increase in $\mathrm{MBF}$ was significantly greater than that elicited by the maximal hypercapnic stimulus of $60 \mathrm{~mm} \mathrm{Hg}(2.00$ vs. $0.86 \mathrm{~mL} / \mathrm{min} / \mathrm{g} ; P<0.0001)$.

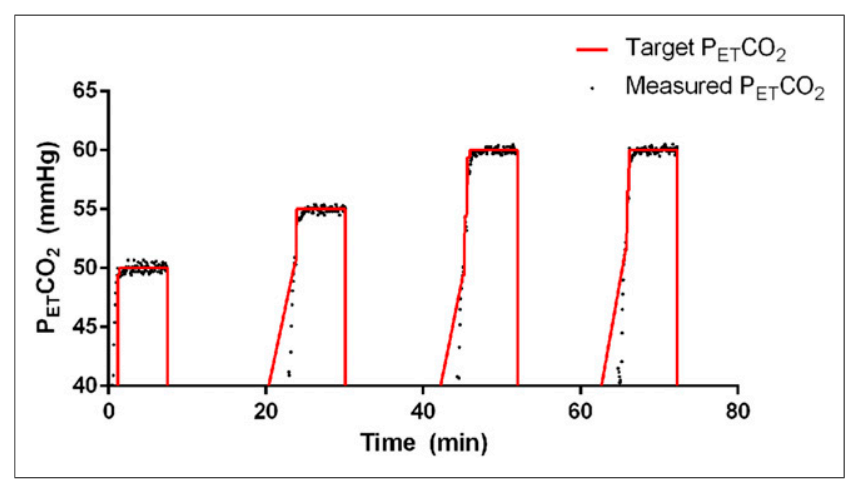

FIGURE 2. Representative curve of target $\mathrm{P}_{\mathrm{ET}} \mathrm{CO}_{2}$ (red line) and measured $\mathrm{P}_{\mathrm{ETCO}}$ (black dots) in participant at different levels of hypercapnia. 


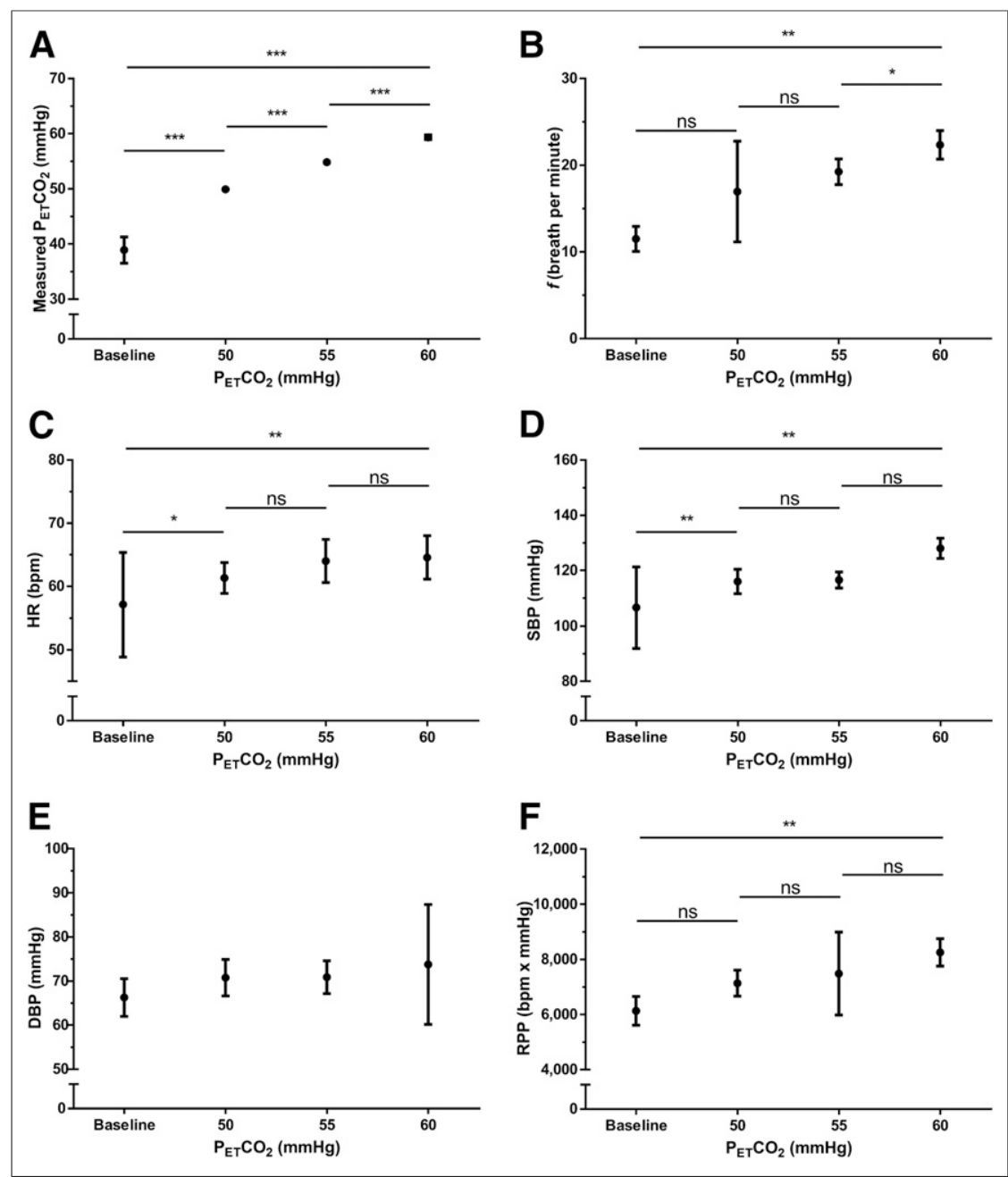

FIGURE 3. Measured $\mathrm{P}_{\mathrm{ET}} \mathrm{CO}_{2}(\mathrm{~A}), f(\mathrm{~B}), \mathrm{HR}(\mathrm{C}), \mathrm{SBP}(\mathrm{D}), \mathrm{DBP}(\mathrm{E})$, and RPP $(\mathrm{F})$ of all participants at baseline and at different levels of hypercapnia. Results are presented as mean \pm SD. $P$ values of $\geq 0.05$ were not significant (ns). ${ }^{\star} P<0.05$. ${ }^{\star \star} P<0.01$. ${ }^{\star \star *} P<0.0001$.

\section{Reproducibility}

The interval between the first and second $60-\mathrm{mm} \mathrm{Hg}$ acquisitions averaged $24.8 \pm 8.3 \mathrm{~min}$ (range, $12-41 \mathrm{~min}$ ). $\mathrm{MBF}$ at the repeat $60-\mathrm{mm} \mathrm{Hg}$ stimulus was not significantly different from at the initial $60-\mathrm{mm} \mathrm{Hg}$ one $(0.87$ vs. $0.86 \mathrm{~mL} / \mathrm{min} / \mathrm{g} ; P=0.051)$ (Fig. 6A). This finding remained true when correction for RPP was used (0.64 vs. $0.59 \mathrm{~mL} / \mathrm{min} / \mathrm{g} ; P=0.434)$. Finally, MFR was, on average, marginally greater at the repeat $60-\mathrm{mm} \mathrm{Hg}$ level than at the initial $60-\mathrm{mm} \mathrm{Hg}$ stress $(2.12$ vs. $1.97 ; P=$ 0.019) (Fig. 6B).

\section{Study Tolerability}

For 7 subjects, hypercapnia was more tolerable than adenosine, whereas for 2 subjects, adenosine was more tolerable than hypercapnia. In 1 subject, both stimuli were equally tolerable. Average tolerability scores for hypercapnic and adenosine stimuli did not significantly differ $(4.5 \pm 2.0$ vs. $6.0 \pm 2.5 ; P=0.15)$.

\section{DISCUSSION}

To our knowledge, this study in healthy young men is the first documentation of a dose-response curve for $\mathrm{CO}_{2}$ and $\mathrm{MBF}$ with
PET. MBF increased progressively with hypercapnia, reaching a doubling of the baseline $\mathrm{MBF}$ at a $\mathrm{P}_{\mathrm{ETCO}_{2}}$ of $60 \mathrm{~mm} \mathrm{Hg}$. Although some animal studies showed no change in MBF with hypercapnia $(18,19)$, our results are consistent with those of other animal studies reporting an increase in MBF with hypercapnia $(7,8,20,21)$. Beaudin et al. (22), using cardiac MRI, demonstrated an increase of $34 \%$ in coronary sinus flow with a $\mathrm{PaCO}_{2}$ of $45 \mathrm{~mm} \mathrm{Hg}$. Tzou et al. (23) demonstrated that hypercapnia increased by approximately $40 \%$ the coronary blood flow velocity of the left anterior descending coronary artery, as measured with transthoracic Doppler echocardiography. Furthermore, this increase in blood flow velocity was greater at higher levels of inspired $\mathrm{CO}_{2}$. Similar results were obtained with invasive measurements of coronary sinus flow (24).

However, other studies with Doppler echocardiography and PET showed little or no increase in MBF with hypercapnia $(25,26)$. In these studies, the application of fixed inspired $\mathrm{CO}_{2}$ concentrations elicited unreliable increases in $\mathrm{PaCO}_{2}$ (14); indeed, when measured, $\mathrm{PaCO}_{2}$ had barely changed, if at all (25). However, these studies in humans were hampered by the inability to attain and maintain the specific $\mathrm{PCO}_{2}$ levels needed to generate an $\mathrm{MBF}-\mathrm{PCO}_{2}$ relationship or to separate the direct effects of $\mathrm{CO}_{2}$ from the secondary effects of increases in myocardial work due to hypercapniainduced increases in $\mathrm{HR}$ and SBP $(22,24,26)$. In our young subjects, these secondary effects were mild but contributed to the increase in MBF (Fig. 4).

We also found that hypercapnia elicited reproducible changes in $\mathrm{MBF}$ with a repeat $\mathrm{P}_{\mathrm{ET}} \mathrm{CO}_{2}$ stimulus of $60 \mathrm{~mm} \mathrm{Hg}$. In contrast, the pharmacokinetics of intravenous agents resulted in unpredictable blood levels and time courses of the effects (see Fierstra et al. (10) for a discussion). Hypercapnia in the range of $60 \mathrm{~mm} \mathrm{Hg}$ is high but not outside the range commonly encountered in adults in the community. For example, in people with obstructive sleep apnea, such levels occur as often as 5-20 times/h all night (27). Hypercapnia does not cause irreversible adverse effects, even in patients with underlying morbidities (28-30). A $\mathrm{P}_{\mathrm{ETCO}}$ of $60 \mathrm{~mm} \mathrm{Hg}$ was well tolerated by all subjects in the present study. As such, hypercapnia may be considered a candidate in the search for an MBF stimulus that is noninvasive, tolerable, safe, rapidly reversible and, most importantly, reproducible-in terms of both stimulus and response.

An increase in RPP, a proxy of cardiac work, with hypercapnia is associated with increased myocardial work and oxygen consumption (31), leading to increased MBF. In the present study, hypercapnia increased both HR and SBP, consistent with previous results in humans $(32,33)$. After correction for RPP, there was still a significant increase in MBF. This result was confirmed by multiple variable regression analyses demonstrating independent 


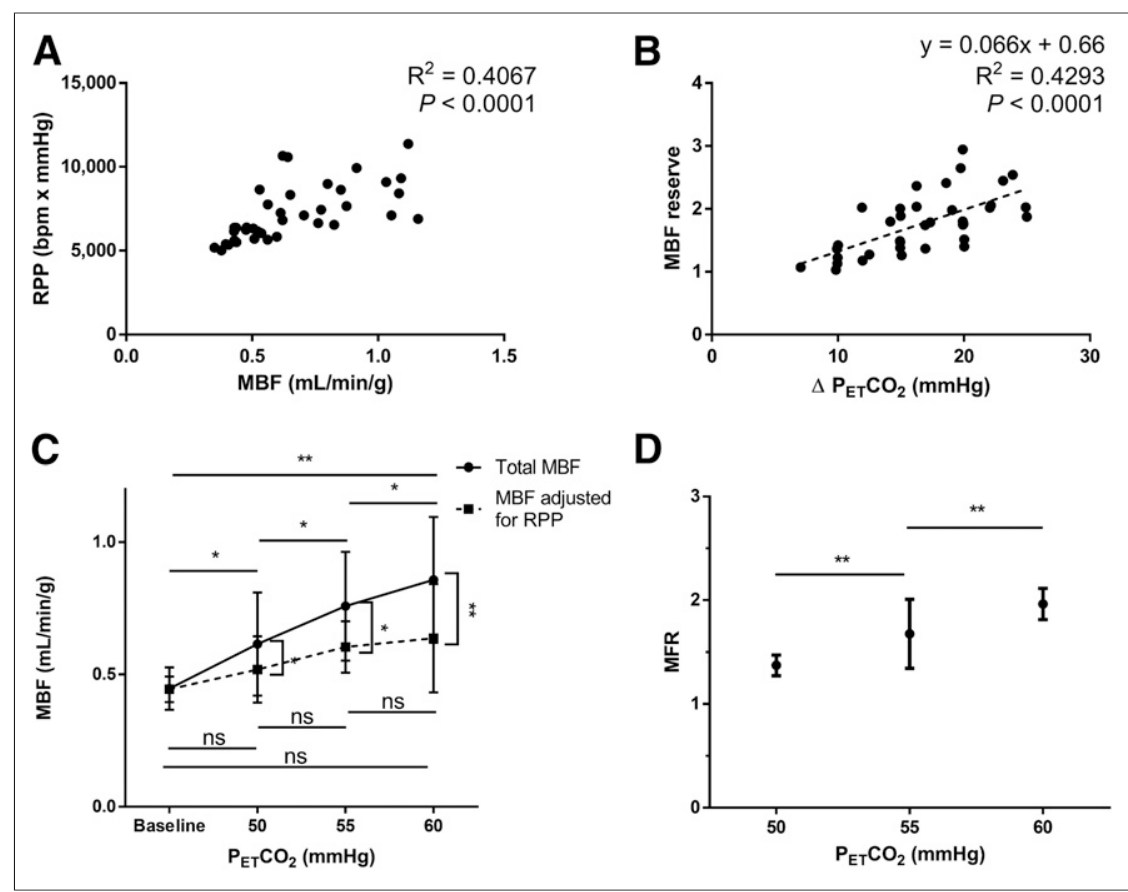

FIGURE 4. (A) MBF vs. RPP. (B) MFR vs. increase in $\mathrm{P}_{\mathrm{ET}} \mathrm{CO}_{2}$. (C) Relationships between MBF and $\mathrm{P}_{\mathrm{ET}} \mathrm{CO}_{2}$ and between adjusted MBF and $\mathrm{P}_{\mathrm{ET}} \mathrm{CO}_{2}$. (D) Relationship between MFR and hypercapnia. Results are presented as mean \pm SD. ${ }^{*} P<0.05$. ${ }^{* *} P<0.01$.

contributions of RPP and $\mathrm{P}_{\mathrm{ETCO}}$. These data suggest that the increase in MBF can be partially, but not completely, attributed to increased cardiac work. If the increase in MBF due to increased myocardial work is assumed to be proportional to the increase in RPP, then approximately half of the increase in MBF was due to increased cardiac work. The other half likely was related to the direct vasodilatation effect of hypercapnia. Indeed, prior studies demonstrated that hypercapnia dilates the coronary arteries, a phenomenon mediated by endothelium-derived nitric oxide, adrenergic stimulus, and other mechanisms yet to be determined (3,34-36). At similar $\mathrm{P}_{\mathrm{ETCO}}$ levels in healthy young subjects, Claassen et al. (37) observed a $23 \%$ increase in the mean arterial pressure with an SBP of up to $160 \mathrm{~mm} \mathrm{Hg}$, which would have increased RPP considerably more than the conditions in the present study and which would have provided greater stress. Like them, we found hypertensive responses plateauing as $\mathrm{P}_{\mathrm{ETCO}}$ approached $60 \mathrm{~mm} \mathrm{Hg}$.

In all subjects, adenosine injection increased MBF more than the maximal hypercapnic stimulus, with an average MFR of 4.53 for adenosine stress. On the one hand, this finding is consistent with previously published results reporting an MFR of 4 to 5 after adenosine stress and shows that our subjects had normal or above-normal coronary flow reserve (38). On the other hand, this result differs from the recently published observations of Yang et al. (8), who evaluated changes in $\mathrm{MBF}$ with hypercapnia $\left(\mathrm{PaCO}_{2}\right.$ increased by $25 \mathrm{~mm} \mathrm{Hg}$ ) and adenosine stresses in canines without coronary stenosis, with nonflow-limiting coronary stenosis, and after caffeine administration. In canines without coronary stenosis, increases in MBF did not differ in response to hypercapnia and adenosine, doubling relative to the baseline level (8). Similar results were observed using myocardial blood oxygen level-dependent MRI (7).

We observed similar MFR levels with hypercapnia, but MFR was greater with adenosine. These findings could have been related to the fact that the effects of adenosine on MBF are speciesdependent and a standard dose of adenosine $(140 \mu \mathrm{g} / \mathrm{kg} / \mathrm{min})$ is insufficient to produce maximal hyperemia in canines (39). Nevertheless, the increases in MBF with hypercapnia were similar in magnitude to previously reported increases during exercise stress $(1.8-2.0)(38,40)$ and with dipyridamole $(41,42)$. Our subject population overlaps the coronary stress test population, some of whom also are young and have normal coronary anatomy. A definitive answer as to what extent hypercapnia can substitute for exercise and dipyridamole would require head-to-head comparisons of exercise versus hypercapnia and dipyridamole versus hypercapnia in a coronary stress test population.

Finally, we showed that the effect of hypercapnia on MBF was reproducible; $\mathrm{MBF}$ and corrected $\mathrm{MBF}$ with the first and repeat 60-mm $\mathrm{Hg}$ stimuli did not differ. The finding that MFR was $8 \%$

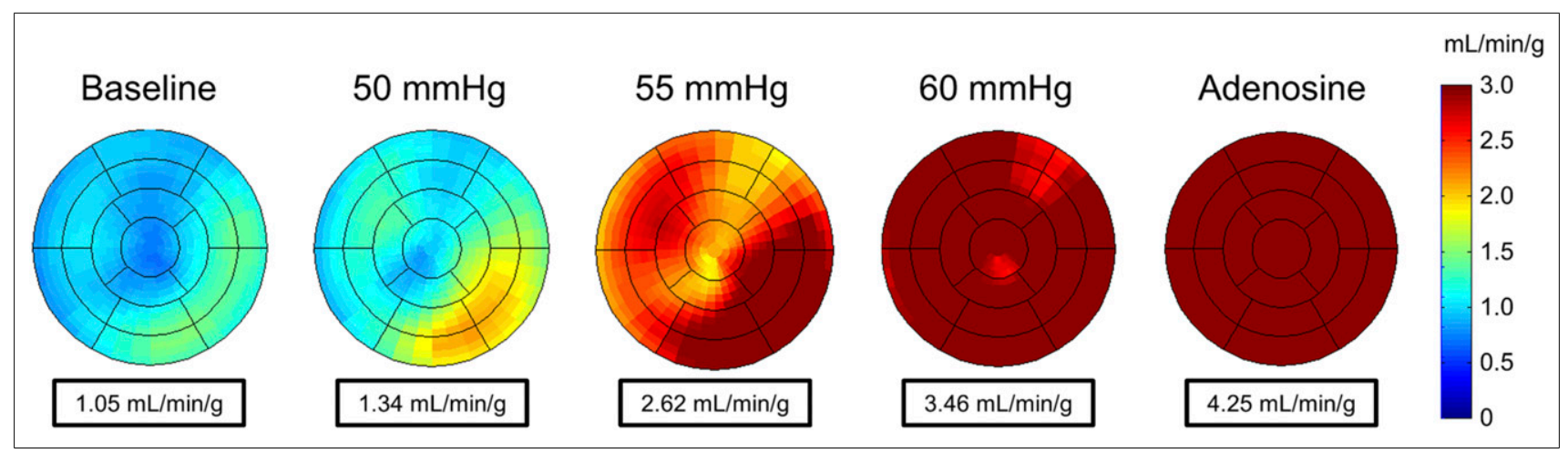

FIGURE 5. MBF polar maps of representative subject, showing global MBF at baseline, during hypercapnic stimuli, and during adenosine stress. 


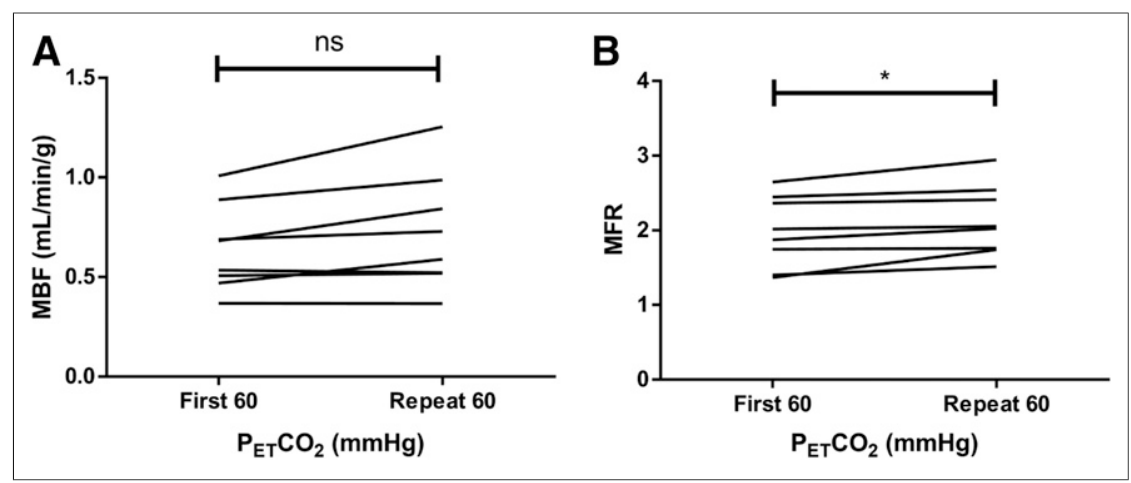

FIGURE 6. Average MBF (A) and MFR (B) during initial and repeat $60-\mathrm{mm} \mathrm{Hg} \mathrm{P}_{\mathrm{ET}} \mathrm{CO}_{2}$ stress. Results are presented as mean \pm SD. $P$ values of $\geq 0.05$ were not significant. ${ }^{*} P<0.05$.

\section{ACKNOWLEDGMENTS}

We thank Farrah Ahmed, Brian Marvin, and Marlie Poirier of the University of Ottawa Heart Institute, Ottawa, Ontario, Canada, for their contribution in the collection of data. We thank Steve Iscoe for editorial comments.

\section{REFERENCES}

1. Barcroft J, Dixon WE. The gaseous metabolism of the mammalian heart: part I. J Physiol (Lond). 1907;35:182-204.

2. Markwalder J, Starling EH. A note on some factors which determine the blood-flow through the coronary circulation. J Physiol (Lond). 1913;47:275285.

greater on repeat measurements may have been due to a combination of test-retest variability and the effects of the intervening rest period of 12-41 min with free breathing of room air, whereas the initial $60-\mathrm{mm} \mathrm{Hg}$ acquisition was performed soon after the 50- and 55- $\mathrm{mm} \mathrm{Hg}$ acquisitions. Indeed, this finding may have been partly attributable to the fact that the MBF response to an increase in $\mathrm{PaCO}_{2}$ decreased during prolonged ( $>10$ min) hypercapnia (3).

The main limitation of this study pertained to the population studied. Our subjects were all healthy male volunteers with low resting MBF (female subjects were not purposely excluded; all of the volunteers were male). Whether similar results would be obtained with different populations, such as patients with $\mathrm{CAD}$ and subjects with high resting $\mathrm{MBF}$, remains to be determined.

\section{CONCLUSION}

To our knowledge, this study is the first to assess changes in MBF in response to different levels of hypercapnia in humans with PET. MBF increased at each incremental $\mathrm{P}_{\mathrm{ETCO}}$ level up to $60 \mathrm{~mm} \mathrm{Hg}$. Approximately half of this increase could be attributed to increased cardiac work, as indicated by the RPP. With the maximal hypercapnic stimulus of $60 \mathrm{~mm} \mathrm{Hg}$, MBF doubledcomparable to the increase in MBF obtained with exercise stress. Larger increases in RPP due to hypercapnia may increase MBF further.

Hypercapnia has additional characteristics to commend it for clinical investigation: it is readily available, inexpensive, and an intrinsic molecule that can be precisely, consistently, and reproducibly administered by automated delivery systems. It is well tolerated at the effective partial pressure of $60 \mathrm{~mm} \mathrm{Hg}$, and it is safe even at multiple times its effective dose, giving it a large safety margin as a drug. The rapid onset and offset of $\mathrm{PCO}_{2}$ levels and the consistency of MBF with repeated hypercapnia tests commend it for repeated tests in a single session, as is sometimes required in clinical practice. To assess the potential clinical impact of hypercapnia in the diagnosis of CAD, further investigations comparing $\mathrm{MBF}$ with hypercapnia versus pharmacologic stress or exercise in patients with CAD are warranted.

\section{DISCLOSURE}

No potential conflict of interest relevant to this article was reported.
3. Ledingham IM, McBride TI, Parratt JR, Vance JP. The effect of hypercapnia on myocardial blood flow and metabolism. J Physiol (Lond). 1970;210:87-105.

4. Alexander CS, Liu SM. Effect of hypercapnia and hypocapnia on myocardial blood flow and performance in anaesthetized dogs. Cardiovasc Res. 1976;10:341-348.

5. Hoffman WE, Albrecht RF, Ripper R, Jonjev ZS. Brain compared to heart tissue oxygen pressure during changes in arterial carbon dioxide in the dog. J Neurosurg Anesthesiol. 2001;13:303-309.

6. Feigl EO. Coronary physiology. Physiol Rev. 1983;63:1-205.

7. Yang HJ, Yumul R, Tang R, et al. Assessment of myocardial reactivity to controlled hypercapnia with free-breathing T2-prepared cardiac blood oxygen leveldependent MR imaging. Radiology. 2014;272:397-406.

8. Yang $\mathrm{HJ}$, Dey D, Sykes J, et al. Arterial $\mathrm{CO}_{2}$ as a potent coronary vasodilator: a preclinical PET/MR validation study with implications for cardiac stress testing. J Nucl Med. 2017;58:953-960.

9. Schelbert HR. Positron emission tomography measurements of myocardial blood flow: assessing coronary circulatory function and clinical implications. Heart. 2012;98:592-600.

10. Fierstra J, Sobczyk O, Battisti-Charbonney A, et al. Measuring cerebrovascular reactivity: what stimulus to use? J Physiol (Lond). 2013;591:5809-5821.

11. Slessarev M, Han J, Mardimae A, et al. Prospective targeting and control of end-tidal $\mathrm{CO}_{2}$ and $\mathrm{O}_{2}$ concentrations. J Physiol (Lond). 2007;581:1207-1219.

12. Efseaff M, Klein R, Ziadi MC, Beanlands RS, deKemp RA. Short-term repeatability of resting myocardial blood flow measurements using rubidium-82 PET imaging. J Nucl Cardiol. 2012;19:997-1006.

13. Dekemp RA, Declerck J, Klein R, et al. Multisoftware reproducibility study of stress and rest myocardial blood flow assessed with 3D dynamic PET/CT and a 1-tissue-compartment model of ${ }^{82} \mathrm{Rb}$ kinetics. J Nucl Med. 2013;54:571-577.

14. Fisher JA. The $\mathrm{CO}_{2}$ stimulus for cerebrovascular reactivity: fixing inspired concentrations vs. targeting end-tidal partial pressures. J Cereb Blood Flow Metab. 2016;36:1004-1011.

15. Fisher JA, Iscoe S, Duffin J. Sequential gas delivery provides precise control of alveolar gas exchange. Respir Physiol Neurobiol. 2016;225:60-69.

16. Ito S, Mardimae A, Han J, et al. Non-invasive prospective targeting of arterial $\mathrm{P}\left(\mathrm{CO}_{2}\right)$ in subjects at rest. J Physiol (Lond). 2008;586:3675-3682.

17. Spano VR, Mandell DM, Poublanc J, et al. $\mathrm{CO}_{2}$ blood oxygen level-dependent MR mapping of cerebrovascular reserve in a clinical population: safety, tolerability, and technical feasibility. Radiology. 2013;266:592-598.

18. Powers ER, Bannerman KS, Fitz-James I, Cannon PJ. Effect of elevations of coronary artery partial pressure of carbon dioxide $\left(\mathrm{PCO}_{2}\right)$ on coronary blood flow. J Am Coll Cardiol. 1986;8:1175-1181.

19. Case RB, Greenberg H. The response of canine coronary vascular resistance to local alterations in coronary arterial $\mathrm{P} \mathrm{CO}_{2}$. Circ Res. 1976;39:558-566.

20. Love WD, Tyler MD, Abraham RE, Munford RS. Effects of $\mathrm{O}_{2}, \mathrm{CO}_{2}$, and drugs on estimating coronary blood flow from RB86 clearance. Am J Physiol. 1965;208:1206-1210.

21. Feinberg $\mathrm{H}$, Gerola A, Katz LN. Effect of changes in blood $\mathrm{CO}_{2}$ level on coronary flow and myocardial $\mathrm{O}_{2}$ consumption. Am J Physiol. 1960;199:349-354.

22. Beaudin AE, Brugniaux JV, Vöhringer M, et al. Cerebral and myocardial blood flow responses to hypercapnia and hypoxia in humans. Am J Physiol Heart Circ Physiol. 2011;301:H1678-H1686. 
23. Tzou WS, Korcarz CE, Aeschlimann SE, Morgan BJ, Skatrud JB, Stein JH. Coronary flow velocity changes in response to hypercapnia: assessment by transthoracic Doppler echocardiography. $J$ Am Soc Echocardiogr. 2007;20:421-426.

24. Kazmaier S, Weyland A, Buhre W, et al. Effects of respiratory alkalosis and acidosis on myocardial blood flow and metabolism in patients with coronary artery disease. Anesthesiology. 1998;89:831-837.

25. Momen A, Mascarenhas V, Gahremanpour A, et al. Coronary blood flow responses to physiological stress in humans. Am J Physiol Heart Circ Physiol. 2009;296:H854-H861.

26. Yokoyama I, Inoue Y, Kinoshita T, Itoh H, Kanno I, Iida H. Heart and brain circulation and $\mathrm{CO}_{2}$ in healthy men. Acta Physiol (Oxf). 2008;193:303-308.

27. Chin $\mathrm{K}$, Hirai $\mathrm{M}$, Kuriyama $\mathrm{T}$, et al. Changes in the arterial $\mathrm{PCO}_{2}$ during a single night's sleep in patients with obstructive sleep apnea. Intern Med. 1997;36:454-460.

28. Feihl F, Perret C. Permissive hypercapnia: how permissive should we be? Am J Respir Crit Care Med. 1994;150:1722-1737.

29. Potkin RT, Swenson ER. Resuscitation from severe acute hypercapnia: determinants of tolerance and survival. Chest. 1992;102:1742-1745.

30. Ayas N, Bergstrom LR, Schwab TR, Narr BJ. Unrecognized severe postoperative hypercapnia: a case of apneic oxygenation. Mayo Clin Proc. 1998;73:51-54.

31. Gobel FL, Norstrom LA, Nelson RR, Jorgensen CR, Wang Y. The rate-pressure product as an index of myocardial oxygen consumption during exercise in patients with angina pectoris. Circulation. 1978;57:549-556.

32. Kiely DG, Cargill RI, Lipworth BJ. Effects of hypercapnia on hemodynamic, inotropic, lusitropic, and electrophysiologic indices in humans. Chest. 1996; 109:1215-1221.

33. Battisti-Charbonney A, Fisher JA, Duffin J. Respiratory, cerebrovascular and cardiovascular responses to isocapnic hypoxia. Respir Physiol Neurobiol. 2011;179:259-268.
34. Weinberger SE, Schwartzstein RM, Weiss JW. Hypercapnia. N Engl J Med. 1989;321:1223-1231.

35. Fierstra J, Maclean DB, Fisher JA, et al. Surgical revascularization reverses cerebral cortical thinning in patients with severe cerebrovascular steno-occlusive disease. Stroke. 2011;42:1631-1637.

36. Guensch DP, Fischer K, Flewitt JA, et al. Breathing manoeuvre-dependent changes in myocardial oxygenation in healthy humans. Eur Heart J Cardiovasc Imaging. 2014;15:409-414.

37. Claassen JAHR, Zhang R, Fu Q, Witkowski S, Levine BD. Transcranial Doppler estimation of cerebral blood flow and cerebrovascular conductance during modified rebreathing. J Appl Physiol. 2007;102:870-877.

38. Wyss CA, Koepfli P, Mikolajczyk K, Burger C, von Schulthess GK, Kaufmann PA. Bicycle exercise stress in PET for assessment of coronary flow reserve: repeatability and comparison with adenosine stress. J Nucl Med. 2003;44:146-154.

39. Jeremias A, Filardo SD, Whitbourn RJ, et al. Effects of intravenous and intracoronary adenosine $5^{\prime}$-triphosphate as compared with adenosine on coronary flow and pressure dynamics. Circulation. 2000;101:318-323.

40. Krivokapich J, Smith GT, Huang SC, et al. ${ }^{13} \mathrm{~N}$ ammonia myocardial imaging at rest and with exercise in normal volunteers: quantification of absolute myocardial perfusion with dynamic positron emission tomography. Circulation. 1989;80:1328-1337.

41. Renaud JM, DaSilva JN, Beanlands RS, DeKemp RA. Characterizing the normal range of myocardial blood flow with ${ }^{82}$ rubidium and ${ }^{13} \mathrm{~N}$-ammonia PET imaging. J Nucl Cardiol. 2013;20:578-591.

42. Ziadi MC, Dekemp RA, Williams KA, et al. Impaired myocardial flow reserve on rubidium-82 positron emission tomography imaging predicts adverse outcomes in patients assessed for myocardial ischemia. J Am Coll Cardiol. 2011;58:740-748. 